\title{
2-Mercaptobenzimidazole, 2-Mercaptobenzothiazole, and Thioglycolic Acid in an Electroless Nickel-Plating Bath
}

\author{
Ahmet Ozan Gezerman and Burcu Didem Çorbacıŏlu \\ Department of Chemical Engineering, Faculty of Chemical and Metallurgical Engineering, Yildiz Technical University, \\ 34220 Istanbul, Turkey
}

Correspondence should be addressed to Ahmet Ozan Gezerman; ahmet_ozan@yahoo.com

Received 11 August 2015; Accepted 22 October 2015

Academic Editor: Takeshi Kondo

Copyright ( 2015 A. O. Gezerman and B. D. Corbacioğlu. This is an open access article distributed under the Creative Commons Attribution License, which permits unrestricted use, distribution, and reproduction in any medium, provided the original work is properly cited.

\begin{abstract}
The use of three different materials, 2-mercaptobenzimidazole, 2-mercaptobenzothiazole, and thioglycolic acid, was investigated to improve the performance of electroless nickel-plating baths. By changing the concentrations of these materials, sample plates were coated. Optical microscope images were obtained by selecting representative coated plates. From the results of the investigations, the effects of these materials on electroless nickel plating were observed, and the most appropriate amounts of these materials for nickel plating were determined. Moreover, the nickel plating speed observed with the bath solution containing 2-mercaptobenzimidazole, 2-mercaptobenzothiazole, and thioglycolic acid is higher than that in the case of traditional electroless plating baths, but the nickel consumption amount in the former case is lower. In order to minimize the waste water generated from electroless nickel-plating baths, we determined the lowest amounts of the chemicals that can be used for the concentrations reported in the literature.
\end{abstract}

\section{Introduction}

There have been several important developments in plating technologies recently. One reason for this is the important functional abilities of plating materials. The development of coating materials may involve high costs, but because coated materials have long lifetimes, this disadvantage can be mitigated. Electroless nickel plating is used for many purposes in the metal industry, and its usage is increasing every year because nickel-plated materials change the functional properties of substrates.

Electroless nickel plating imparts perfect corrosion resistance and abrasive properties to the substrate. It is also independent of the material shape and provides uniform plating thickness. Therefore, electroless nickel plating is used in the petroleum, chemical, plastic, optics, mining, nuclear, automotive and food industries.

Differences in the electroless nickel-plating method compared to other plating techniques include not only electrical current in the electrolyte, but also the presence of nonmetallic materials in the solution, with $88-95 \%$ nickel metal bonded onto the metal surface. Because nickel ions and nonmetallic elements such as phosphorus take part in the plating process, an amorphous layer, which is called the metallic glass layer, is formed. Electroless nickel plating is a chemical reduction technique that is autocatalytic. When the microstructure is observed, crystals are not present in the plating layer, unlike galvanic cells where crystals are formed. Unlike coatings that are plated using other electrolytic techniques, electroless nickel is not sacrificial plating. Because it forms a uniform thickness on the substrate, in contrast to electrolytic coatings that show a difference in thickness with current densities, it behaves as a barrier coating that isolates the substrate from the ambient. This plating method has special features that are unrivalled, and it is also preferred over other plating techniques in many industries.

There are several applications of electroless nickel plating in the metal industry. Yee et al. created a palladium-copper interlayer in nickel plating by adding copper for improving the physical properties of nickel plating [1]. Shao et al. studied a different process by plating nickel on a magnesium alloy [2]. Liu et al. contributed to industrial development by studying the recovery of high-purity ferric phosphate [3]. In another work, Fujii et al. achieved electroless nickel plating on 
polymer particles [4]. Rajaguru et al. contributed importantly to the metal plating industry by performing electroless nickel plating for low-volume production of plastic parts [5]. Yim et al. plated nickel electrolessly on pitch-based carbon fiber reinforced composites. These studies showed that physical properties such as hardness were improved [6]. Jin et al. prepared grafted carbon fibers by electrochemically mediated atom transfer radical polymerization. They investigated the adsorption of $\mathrm{Ni}^{2+}$ on these grafted carbon fibers in an electroless nickel-plating bath [7]. The process of nickel plating creates an important problem such as the recovery of nickel. Li et al. studied the recovery of nickel in industrial processes [8]. In another study by Shu et al., nickel particles were activated by using thiourea dioxide [9]. Liu et al. determined new methods for the electroless nickel-plating process by using complex salts that contain $\mathrm{Li}$ and $\mathrm{Fe}[10]$. Tengsuwan et al. [11] used supercritical carbon dioxideassisted nickel plating to fabricate polymer particles. An integrated electroless nickel-plating process was developed for CMOS (Complementary Metal Oxide Semiconductor) MEMS (Micro-Electromechanical System) by Lee et al. [12]. From the viewpoint of industrial development, the characterization of electroless nickel-coated cellulose fibers was investigated by Sittisart et al. [13]. Lee et al. presented a new method of recovering nickel that involved electrolysis of spent electroless nickel-plating solutions comprising hexasulfonate salt [14]. Ajibola et al. [15] contributed to industrial development by studying electroless nickel plating using aluminum alloys. The recovery of Ni metal, $\mathrm{P}$, and $\mathrm{S}$ from process baths for plated double-hydroxide composites by electroless nickel plating has been studied by Zhu et al. [16]. Another work from the viewpoint of industrial development is a study on arcdischarge-synthesized carbon nanotubes for metal matrix composites; this study was performed by Jagannatham et al. [17].

The recovery of nickel is an important aspect of nickelplating processes, and there are many studies regarding this. Nickel recovery using a Counter Current Emulsion Flow Extractor is an interesting example in this regard [18].

In the present study, the effects of compositions that contain 2-mercaptobenzimidazole, 2-mercaptobenzothiazole, and thioglycolic acid were investigated to improve physical properties such as corrosion resistance and mechanical strength.

\section{Experimental Procedure}

In this study, three different chemicals were used in the electroless nickel-plating baths, and the crystal structure of the coated materials and their images were observed so that the most ideal composition can be determined.

\subsection{Experimental Procedure}

2.1.1. Compounds Used in the Experiments. 2-Mercaptobenzimidazole, 2-mercaptobenzothiazole sodium salt, and thioglycolic acid were used in the study. Optical microscopy of the coated plates was performed using a Leica DMLM Microscope + QWIN Programme Image Analyser.
TABLE 1: Chemical composition of the first main part solution in a nickel-plating bath.

\begin{tabular}{lcc}
\hline Chemical composition & CAS no. & Concentration $\left(\mathrm{gL}^{-1}\right)$ \\
\hline Distilled water & $7732-18-5$ & 828 \\
Nickel sulfate & $7786-81-4$ & 360 \\
Sulfuric acid & $7664-93-9$ & 32 \\
\hline
\end{tabular}

TABLE 2: Chemical composition of the second main part solution in a nickel-plating bath.

\begin{tabular}{lcc}
\hline Chemical compound & CAS no. & Concentration $\left(\mathrm{gL}^{-1}\right)$ \\
\hline Distilled water & $7732-18-5$ & 309 \\
Potassium hydroxide & $1310-58-3$ & 220 \\
Maleic anhydride & $108-31-6$ & 10 \\
Lactic acid & $50-21-5$ & 133 \\
Glycolic acid & $79-14-1$ & 133 \\
Sodium acetate & $127-09-3$ & 200 \\
Sodium hypophosphite & $10039-56-2$ & 320 \\
\hline
\end{tabular}

2.1.2. Bath Solutions Used in Nickel Plating. An acidic bath was used in electroless nickel plating, and the bath was prepared using two main solutions (Tables 1 and 2). From these two solutions, two baths of $75 \mathrm{~mL}$ and $1 \mathrm{~L}$ were prepared. The $\mathrm{pH}$ was adjusted to 4.8 and the solutions were heated to $90^{\circ} \mathrm{C}$ under working conditions. The chemicals used in this study were obtained from Merck, Istanbul.

2.2. Experimental Procedures. Before plating, the substrate was pretreated by cleaning, then dried, weighed, and labeled. After drying, these material samples were immersed in $2 \%$ sulfuric acid for $2-5 \mathrm{~s}$, rinsed in water, and placed in the electroless nickel-plating bath. Plating was then performed at $90^{\circ} \mathrm{C}$ for $10 \mathrm{~min}$. After plating, all samples were rinsed in tap water, dried, and weighed. Subsequently, the $\mathrm{pH}$ was checked and nickel analysis was conducted.

A total of 5 stainless steel substrates were plated, and the plating ratio for each plate was calculated. A total of five plating baths were prepared. Plating baths $1-5$ were prepared by diluting $75 \mathrm{~mL}$ bath solution to $1 \mathrm{~L}$. The bath compositions and plating results for each bath are shown in Tables 3-7.

Representative samples from the selected substrates were imaged under an optical microscope, and the results are shown in Figures 1(a)-1(e).

2.2.1. Nickel Analysis. A $10 \mathrm{~mL}$ bath solution was placed in an Erlenmeyer flask and $100 \mathrm{~mL}$ distilled water was added to the solution, and then $5 \mathrm{~mL}$ ammonia and approximately $0.5 \mathrm{~g}$ murexide were added. It was immediately titrated with EDTA until a purple color was observed, and the consumption of EDTA (S) was recorded.

Calculations are as follows: $(S) * 0.587=\mathrm{g} / \mathrm{L}$ metallic nickel [16].

The $\mathrm{pH}$ decreased as the plating progressed. Therefore, the $\mathrm{pH}$ was adjusted using dilute ammonia. Nickel sulfate and reduction solutions were prepared for replenishing the material loss during working of the bath. For every $1 \mathrm{~g} / \mathrm{L}$ 


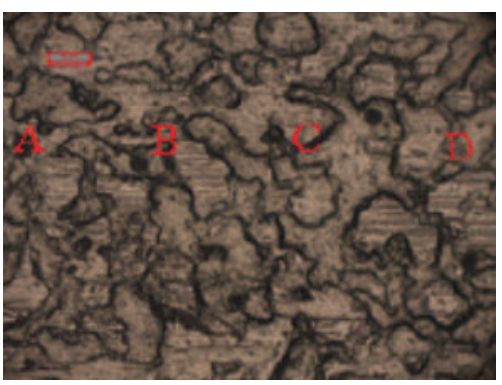

(a)

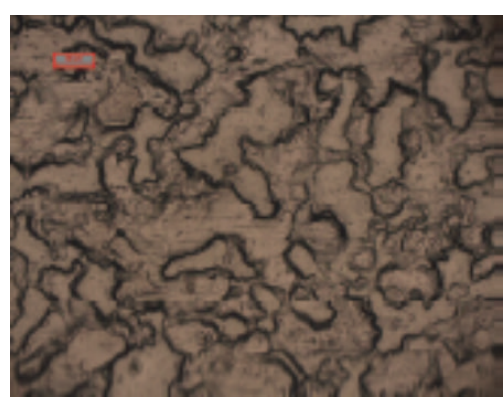

(d)

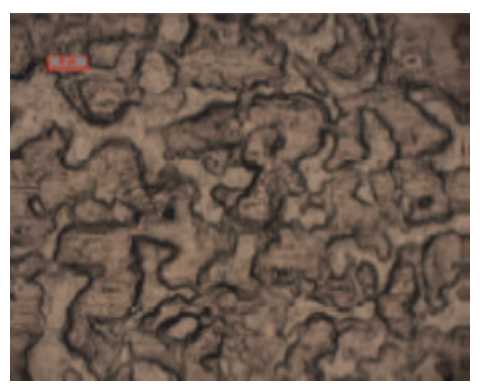

(b)

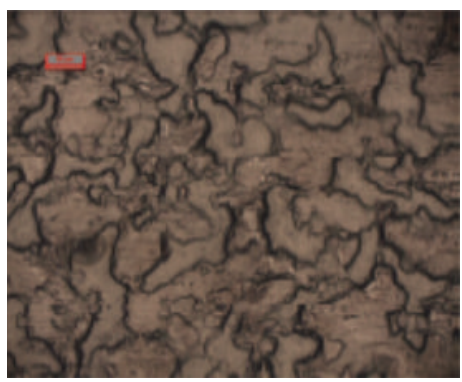

(c)

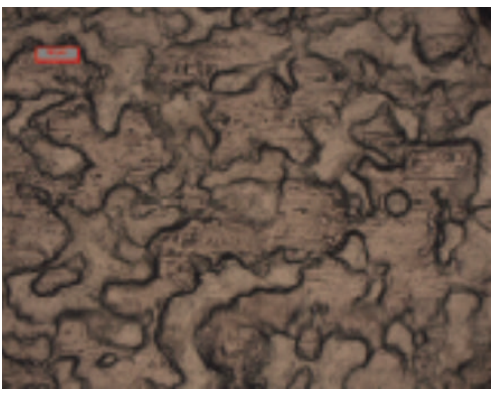

(e)

FIGURE 1: (a) Optical microscope image of plated material no. 1. (b) Optical microscope image of plated material no. 2. (c) Optical microscope image of plated material no. 3. (d) Optical microscope image of plated material no. 4. (e) Optical microscope image of plated material no. 5.

TABLE 3: Plating performed in bath solution no. 1 and results.

\begin{tabular}{lcccc}
\hline Material no. & Chemical additive & Weight before plating $(\mathrm{g})$ & Weight after plating $(\mathrm{g})$ & Plating speed $(\mu / \mathrm{h})$ \\
\hline 01 & No addition & 33.4517 & 33.8962 & 21.40 \\
03 & $2 \mathrm{~mL}$ 2-mercaptobenzimidazole & 33.5632 & 33.5632 & 0 \\
04 & $2 \mathrm{~mL}$ 2-mercaptobenzothiazole & 33.4147 & 33.4147 & 0 \\
05 & $2 \mathrm{~mL}$ thioglycolic acid & 33.7166 & 33.3940 & 0 \\
\hline
\end{tabular}

TABLE 4: Plating performed in bath solution no. 2 and results.

\begin{tabular}{lcccc}
\hline Material no. & Chemical additive & Weight before plating $(\mathrm{g})$ & Weight after plating $(\mathrm{g})$ & Plating speed $(\mu / \mathrm{h})$ \\
\hline 13 & $0.5 \mathrm{~mL}$ 2-mercaptobenzothiazole & 33.9627 & 34.7547 & 25.42 \\
14 & $0.5 \mathrm{~mL}$ 2-mercaptobenzimidazole & 33.4948 & 34.5026 & 32.35 \\
15 & $0.5 \mathrm{~mL}$ thioglycolic acid & 33.6508 & 34.4758 & 26.48 \\
\hline
\end{tabular}

TABLE 5: Plating performed in bath solution no. 3 and results.

\begin{tabular}{lcccc}
\hline Material no. & Chemical additive & Weight before plating $(\mathrm{g})$ & Weight after plating $(\mathrm{g})$ & Plating speed $(\mu / \mathrm{h})$ \\
\hline 25 & $0.3 \mathrm{~mL}$ thioglycolic acid & 33.0866 & 33.8744 & 25.29 \\
26 & $0.3 \mathrm{~mL}$ 2-mercaptobenzothiazole & 32.8369 & 33.4808 & 20.67 \\
27 & $0.3 \mathrm{~mL}$ 2-mercaptobenzimidazole & 33.2579 & 33.9064 & 20.82 \\
\hline
\end{tabular}

TABLE 6: Plating performed in bath solution no. 4 and results.

\begin{tabular}{lcccc}
\hline Material no. & Chemical additive & Weight before plating $(\mathrm{g})$ & Weight after plating $(\mathrm{g})$ & Plating speed $(\mu / \mathrm{h})$ \\
\hline 54 & $0.1 \mathrm{~mL}$ 2-mercaptobenzothiazole & 33.0866 & 33.8744 & 25.29 \\
55 & $0.1 \mathrm{~mL}$ thioglycolic acid & 32.8369 & 33.4808 & 20.67 \\
56 & $0.1 \mathrm{~mL}$ 2-mercaptobenzimidazole & 33.2579 & 33.9064 & 20.82 \\
\hline
\end{tabular}


TABLE 7: Plating performed in bath solution no. 5 and results.

\begin{tabular}{lcccc}
\hline Material no. & Chemical additive & Weight before plating $(\mathrm{g})$ & Weight after plating $(\mathrm{g})$ & Plating speed $(\mu / \mathrm{h})$ \\
\hline 84 & $0.2 \mathrm{~mL}$ thioglycolic acid & 32.6090 & 33.3158 & 34.03 \\
85 & $0.2 \mathrm{~mL}$ 2-mercaptobenzothiazole & 32.6960 & 33.3498 & 31.48 \\
86 & $0.2 \mathrm{~mL}$ 2-mercaptobenzimidazole & 32.5083 & 33.0693 & 27.01 \\
\hline
\end{tabular}

TABLE 8: Components of a reduction solution.

\begin{tabular}{lcc}
\hline Chemical compound & CAS no. & Concentration $\left(\mathrm{gL}^{-1}\right)$ \\
\hline Potassium hydroxide & $1310-58-3$ & 10 \\
Maleic anhydride & $108-31-6$ & 0.5 \\
Lactic acid & $50-21-5$ & 6.7 \\
Glycolic acid & $79-14-1$ & 6.7 \\
Sodium acetate & $127-09-3$ & 6.7 \\
Sodium hypophosphite & $10039-56-2$ & 16.7 \\
2-Mercaptobenzimidazole & $583-39-1$ & \\
2-Mercaptobenzothiazole & $149-30-4$ & \\
Thioglycolic acid & $68-11-1$ & \\
\hline
\end{tabular}

nickel, $10 \mathrm{~mL}$ nickel sulfate solution was added. After this addition, for each $10 \mathrm{~mL}$ of nickel sulfate solution, $8 \mathrm{~mL}$ of reduction solution was added (the reduction solution is described in Section 2.2.2).

2.2.2. Replenishing Solutions. Buffer solutions were prepared to replenish the basic components in the nickel-plating bath, which contained the two main solutions. One of these was the nickel sulfate solution and the other was the hypophosphite solution. This buffer solution is known as the reduction solution.

Nickel sulfate $(45 \mathrm{~g})$ was diluted in distilled water and made up to $100 \mathrm{~mL}$. This solution was used for replenishing the nickel in the plating bath. Compounds as shown in Table 8 were mixed in a beaker and diluted to $100 \mathrm{~mL}$, and the resulting solution was used for replenishing the hypophosphite.

\subsection{Characterization of Physical Properties of Electrolessly Nickel-Plated Layer}

2.3.1. Layer Structure. Layer structure of the electroless nickel was investigated by shear testing [19], which was conducted using a Dage Series 4000 Bond tester. The shear height was determined as $100 \mu \mathrm{m}$ at a shear rate of $550 \mu \mathrm{m} \cdot \mathrm{h}^{-1}$. After shear testing, the fracture surfaces were investigated using SEM (Zeiss Supra 55 scanning electron microscope). An SEM image of the nickel plating formed after the addition of thioglycolic acid is shown in Figure 3(a), while an SEM image of the plating formed after the addition of 2mercaptobenzothiazole is shown in Figure 3(b). Finally, an SEM image of the plating formed after the addition of 2mercaptobenzimidazole is shown in Figure 3(c).

2.3.2. Plating Thickness. It is possible to deposit a uniform plating layer with the required thickness, which typically
TABLE 9: Interdependence of physical parameters in the plating process.

\begin{tabular}{lc}
\hline Adhesion force $\left(\mathrm{kg} \cdot \mathrm{cm}^{-2}\right)$ & Thickness of the nickel plating $(\mu \mathrm{m})$ \\
\hline 0 & 0 \\
2 & 10 \\
2.2 & 11 \\
2.4 & 12 \\
2.6 & 12 \\
2.8 & 14 \\
3.0 & 15 \\
\hline
\end{tabular}

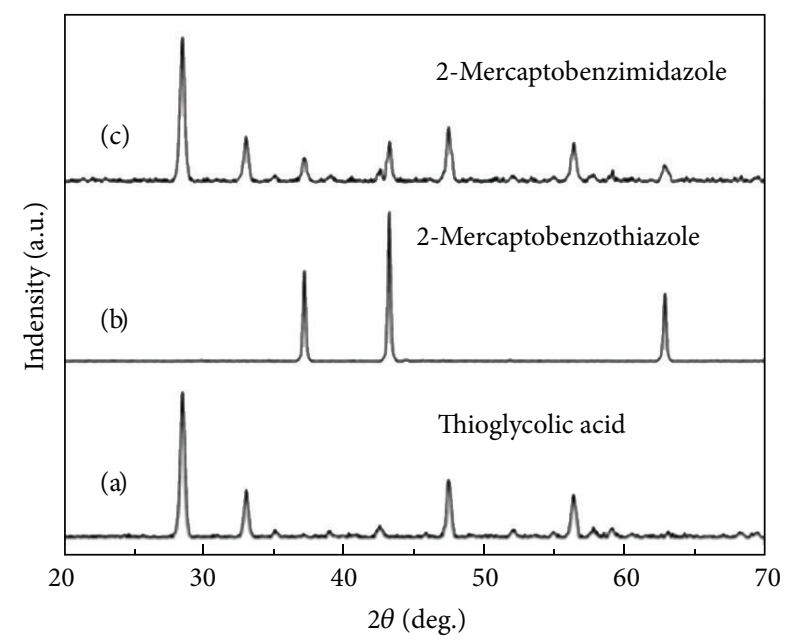

FIGURE 2: XRD patterns of 2-mercaptobenzimidazole, 2-mercaptobenzothiazole, and thioglycolic acid in electroless nickel-plating baths.

lies between 2.5 and $25 \mu \mathrm{m}$. For parts that require higher corrosion resistance, a plating thickness between 25 and $75 \mu \mathrm{m}$ is preferred. If the plating thickness increases, the surface roughness increases. The thickness of the deposited electroless nickel was measured using X-Ray Fluorescence (XRF), and the results are shown in Table 9.

2.3.3. Density. In this study, the density of electroless nickel plating was measured using the associated dimensional change [20]. The thickness of the plated nickel was between 10 and $15 \mu \mathrm{m}$ on the thin side. The mass and dimensions of the test material were measured using a three-coordinate measuring machine, and plating thickness was determined under a graduated-scale microscope after metallographic polishing. 


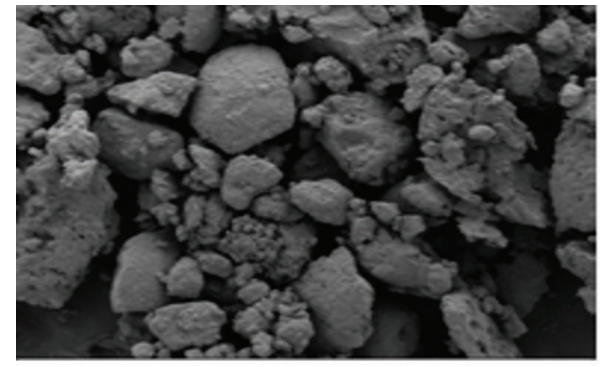

$100 \mu \mathrm{m} \quad \mathrm{EHT}=10.00 \mathrm{kV} \quad$ Signal A $=\mathrm{SE} 2$ Date: 28 Feb $2015 \quad \mathrm{WD}=7.6 \mathrm{~mm}$ Mag $=100 \mathrm{x} \quad$ Time: 10:56:03

(a)

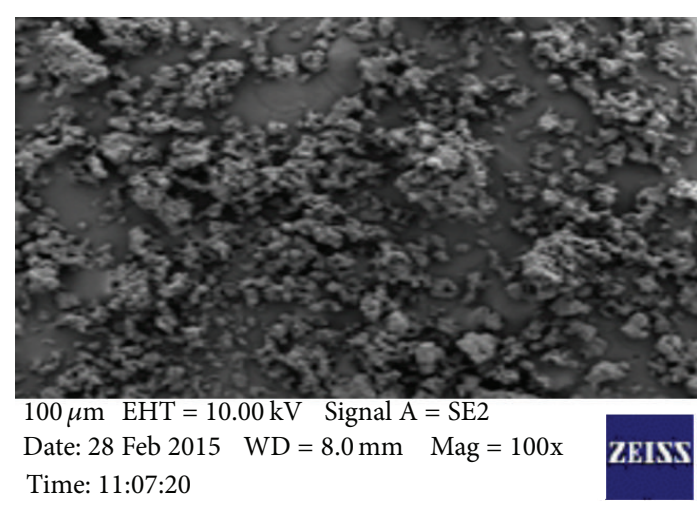

(b)

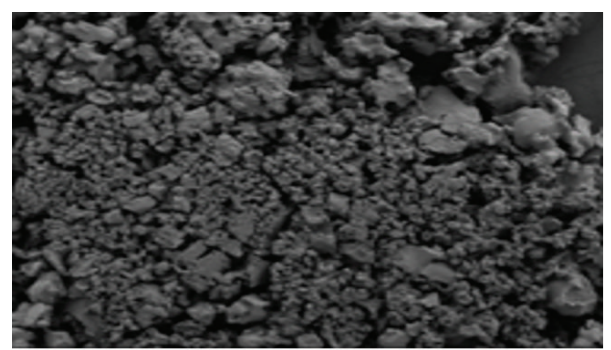

$100 \mu \mathrm{m} \quad \mathrm{EHT}=10.00 \mathrm{kV} \quad$ Signal A $=\mathrm{SE} 2$ Date: 28 Feb 2015 WD $=7.9 \mathrm{~mm}$ Mag $=100 \mathrm{x} \quad$ Time: 11:14:44

(c)

FIGURE 3: (a) SEM image of the nickel plating formed after the addition of thioglycolic acid. (b) SEM image of the nickel plating formed after the addition of 2-mercaptobenzothiazole. (c) SEM image of the nickel plating formed after the addition of 2-mercaptobenzimidazole.

TABLE 10: Electrical resistivity of plated material.

\begin{tabular}{lc}
\hline Bath solution & Electrical resistivity $(\mu \mathrm{cm})$ \\
\hline 1 & 19 \\
2 & 20 \\
3 & 18 \\
4 & 17 \\
5 & 17 \\
\hline
\end{tabular}

2.3.4. Electrical Resistivity. The electrical resistivity was measured using a super-megaohmmeter-type electrometer (Model RM 170) (Table 10).

2.4. Mechanical Properties of Electroless Nickel. Electroless nickel has similar properties to other amorphous platings in that it has high resistance and is elastic. The testing methods and results of the determination of several physical properties such as penetration, hardness, tensile strength, and elongation are explained below.

2.4.1. Penetration. Here, the adhesion strength of the electroless nickel plating was measured by a heat-quench test [21]. In this test, plated materials were heated at $250^{\circ} \mathrm{C}$ for $2 \mathrm{~h}$ and quenched in air.
2.4.2. Hardness. The microhardness of electroless nickel was measured using a diamond indenter [21]. Vickers hardness was obtained by taking the average of the results of five measurements for plating from each bath with a load of $50 \mathrm{~g}$. The microhardness of electroless nickel before heat treatment was in the range of 760-785 HV. An increase in Vickers hardness by 188 to $294 \mathrm{HV}$ was observed after heat treatment at $230 \circ \mathrm{C}$ for $2 \mathrm{~h}$.

2.4.3. Tensile Strength. Tensile strength of the electroless nickel plating prevents any damage to it, and different methods have been developed to measure the tensile strength. In this study, the pull test was used for determining tensile strength.

2.4.4. Pull Test for Tensile Strength. Materials plated using the five bath solutions were subjected to a pull test using a universal testing machine for measuring the tensile strength [21]. The test was successful when there is no separation of the nickel coating from the substrate and it had a tensile strength force of approximately $3500 \mathrm{~N}$. The tensile strength values of the plated materials were examined over the range 3650$3800 \mathrm{~N}$.

2.4.5. Elongation. Elongation is detected using the "Pressure Bulge Test for Thin Film Characterization" [20]. In this 
test, for recording the pressure loading signal, a digital oscilloscope (Nicolet, model 40, bandwidth $100 \mathrm{MHz}$ ) was used, and for recording images after pressure loading, a CCD camera (Sony, XC-75) was used. According to the results of this experiment, the elongation of the plated layer changed from 1.1 to $2.4 \%$.

2.4.6. Optical Images of Electroless Nickel-Plating Layer. Leica DMLM Microscope + QWIN program Image Analyser was used for obtaining optical microscope images of the plated nickel layer.

2.4.7. Wear and Resistance to Abrasion. Abrasion resistance of electroless nickel-plated materials in this study was evaluated according to ASTM D2670-67 [22]. For this analysis, a Falex machine was used.

2.4.8. Friction Characteristics. The friction characteristics of the Ni plating was tested on a fully computerized microtribometer (Model UMT-2) [23], with a friction counterpart of a cemented carbide ball of $5 \mathrm{~mm}$. A load of $5 \mathrm{~N}$ and sliding speed of $2 \mathrm{~mm} \cdot \mathrm{s}^{-1}$ were used, and the total elapsed time for each plated material was $15 \mathrm{~min}$.

\subsubsection{Soldering and Welding on Electroless Nickel Plating}

(1) Preparation of Test Materials. Each test material was prepared from two pieces. These pieces were plated with electroless nickel of approximately $20 \mu \mathrm{m}$ plating thickness. After plating, the two pieces were placed on an aluminum jig and heated on a hot plate to the melting temperature of the solder $\left(350-400^{\circ} \mathrm{C}\right)$ to fill a gap of $0.2 \mathrm{~mm}$ with the solder. Each material piece was moved from the screws of the jig, and after cooling, the soldering parts were machined [21].

2.4.10. Corrosion Resistance. To evaluate the resistance of the electroless nickel coating in a corrosive atmosphere, an accelerated corrosion test was performed, and the potentiodynamic polarization curves were determined. The plated material was placed in a $3.5 \% \mathrm{NaCl}$ solution at a $\mathrm{pH}$ of 7.0 , and the time required for discoloration of the plating as corrosion occurred was recorded. To evaluate the corrosion performance of plated materials in this study, immersion in $3.5 \% \mathrm{NaCl}$ solution for $96 \mathrm{~h}$ was sufficient (see Figure 4). If there was no discoloration on the plated surface in the stipulated time, the test was terminated. In this study, the plated material showed discoloration after 5 days in 3.5\% $\mathrm{NaCl}$ solution. As a result of this experiment, it is concluded that the solderability of the electroless nickel was excellent. It was also resistant to corrosion in $3.5 \% \mathrm{NaCl}$ at a relative humidity of $95 \%$ and temperature of $50^{\circ} \mathrm{C}$ (i.e., as per the ASTM B 117 standard).

\section{Results and Discussion}

Electrolessly plated materials show a glassy metallic structure, known as metallic glass, which is homogeneous and

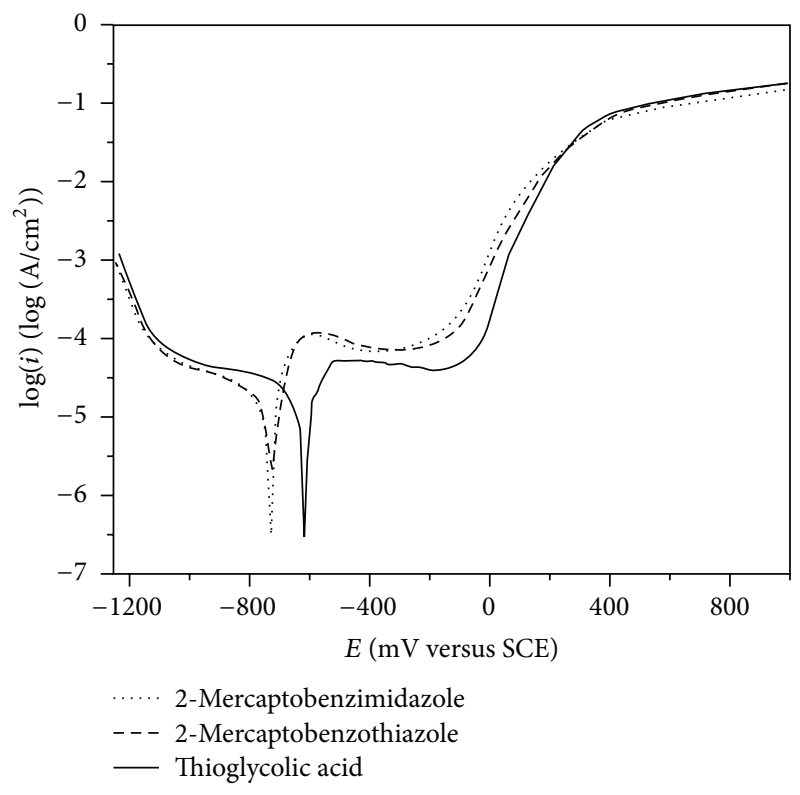

FIGURE 4: Potentiodynamic polarization curves of the nickel platings electrolessly deposited using 2-mercaptobenzimidazole, 2mercaptobenzothiazole, and thioglycolic acid. The measurements were made after the free-corrosion potentials had stabilized and were performed at room temperature in $3.5 \mathrm{wt} \% \mathrm{NaCl}$ at a scan rate of $5 \mathrm{mV} / \mathrm{s}$.

does not contain microvoids. Upon heat treatment, it converts to a structure that contains microvoids [19]. If the amount of phosphorus, which depends on the chemical composition of the bath, changes, the plating rate, layer formation, and mechanical strength will change. Hence, the structure of the plated nickel layer will also change. Further, the concentration of phosphor in the electroless nickel plating was $1-10 \%$ [5]. Shear tests on the layer structure of the plated materials reveal a shear deposition rate of $100 \mu \mathrm{m}$ at $550 \mu \mathrm{m} \cdot \mathrm{h}^{-1}$. The shear deposition rate in the case of the nickel plating containing 2-mercaptobenzimidazole, 2-mercaptobenzothiazole, and thioglycolic acid is higher than that observed when the plating contained only one of the three additives. The plating deposition rate is higher than previously published or patented values [4]. According to the results of shear testing, the shear deposition rates observed for the plating baths containing only 2-mercaptobenzimidazole, thioglycolic acid, or 2mercaptobenzothiazole are $70 \mu \mathrm{m}, 80 \mu \mathrm{m}$, and $95 \mu \mathrm{m}$, respectively. Moreover, when the effects of these three additives on the deposition layers are investigated, interesting results are obtained. The porosity of the material containing one of these three additives decreases in the following order: 2mercaptobenzimidazole $>2$-mercaptobenzothiazole $>$ thioglycolic acid; however, the porosity of the plated material containing the three additives together is much lower than that observed in each of the individual cases stated above.

The plating thickness required for industrial applications ranges between 10 and 20 microns. Electroless plating affords a lower plating thickness than do other plating processes. 2-Mercaptobenzimidazole, thioglycolic acid, and 
2-mercaptobenzothiazole used in this study during nickel plating result in a much narrow range of plating thickness (Table 11). While 2-mercaptobenzimidazole, thioglycolic acid, and 2-mercaptobenzothiazole afford plating thicknesses of $10-15 \mu \mathrm{m}, 11-14 \mu \mathrm{m}$, and $10-14 \mu \mathrm{m}$, respectively, a combination of the three additives gives a plating thickness of $10-$ $12 \mu \mathrm{m}$. X-ray measurements indicate that the plating thickness does not show notable changes on the metal surface. When the aforesaid three additives are used in the plating bath, a uniform plating thickness of $10-12 \mu \mathrm{m}$ is obtained, which is an important advantage of this process, similar to the case of electroless plating. In addition, the effects of 2-mercaptobenzimidazole, 2- mercaptobenzothiazole, and thioglycolic acid on the nickel platings produced were investigated using X-ray diffraction analyses. The XRD pattern of the nickel plating formed after the addition of thioglycolic acid is shown in Figure 2(a); major peaks were seen at $2 \theta$ values of $29.10^{\circ}, 33.120^{\circ}, 48.230^{\circ}$, and $57.130^{\circ}$. Further, the XRD pattern of the nickel plating formed after the addition of 2-mercaptobenzothiazole, shown in Figure 2(b), contained sharp, high-intensity diffraction peaks at $2 \theta$ values of $38.75^{\circ}$, $44.10^{\circ}$, and $64.10^{\circ}$. Finally, the XRD pattern of the plating formed after the addition of 2-mercaptobenzimidazole is shown in Figure 3(c); the diffraction peaks in this spectrum were shifted to higher angles compared to those of the plating produced using a bare bath. This shifting of the peaks to higher diffraction angles was probably owing to the low thickness of the nickel plating. Given the low thickness of the plating, the strain from the epitaxial growth of the plating probably had a significant effect on the plating, resulting in the observed shift in the diffraction peaks.

Uniform plating is important for achieving the required material performance. In electroplating, plating thickness changes depending on the material configuration, geometry, and distance to the anodes. Therefore, it is possible to achieve uniform plating thickness on every part of the material through electroless plating [5]. In the present study, the plating thicknesses were quite uniform over the entire material surface. Therefore, it is concluded that suitable conditions ensure plating uniformity on the surface. As shown in Figure 1(a), four different points were selected for optical imaging of the plated material. Thicknesses measured at these points were similar for the entire surface in a sample (Table 11). Electroless nickel is a eutectic alloy that has a wide range of melting points, and it does not have an absolute melting point. The change in the melting range depends on the phosphorus content; as the phosphorus content decreases, the melting range increases. An increase in the phosphor concentration of $1 \%$ increases the melting point of nickel platings by $2.5^{\circ} \mathrm{C}$ [5].

Thermal properties of electroless nickel are different from the thermal properties of pure nickel such as high temperature oxidation resistance. The melting point of pure nickel is $1455^{\circ} \mathrm{C}$, but the melting point of electroless nickel with different added compounds in the plating bath decreases significantly. In this study, the melting point of electroless nickel that contains 2-mercaptobenzimidazole, 2mercaptobenzothiazole, and thioglycolic acid in the bath was
TABLE 11: Selected points in the plated material in Figure 1(a).

\begin{tabular}{lc}
\hline Signed point & Thickness of the nickel plating $(\mu \mathrm{m})$ \\
\hline A & 10.5 \\
B & 11.1 \\
C & 10.7 \\
D & 10.3 \\
\hline
\end{tabular}

determined to be $1060^{\circ} \mathrm{C}$ according to the eutectic melting bonding (EMB) method [24].

In engineering and automotive industries, high temperature is an important requirement for fuel injection systems, and this necessitates the use of materials that can withstand such temperatures. The melting point of the nickel plating containing phosphorus is $900^{\circ} \mathrm{C}$, while the melting points of the nickel plating containing 2-mercaptobenzimidazole, thioglycolic acid, and 2-mercaptobenzothiazole reach $1060^{\circ} \mathrm{C}$.

Addition of 2-mercaptobenzimidazole, thioglycolic acid, and 2-mercaptobenzothiazole decreases the density of the plating bath solution to below $7.75 \mathrm{~g} \mathrm{~cm}^{-3}$ [5], which is too low to induce sufficient porosity. Therefore, the surface porosity decreases after plating. The electrical resistivity of the nickel-plated material in this study $(30 \Omega)$ is higher than that of the nickel plating containing phosphorus $(20 \Omega)$. The electrical resistivity of the nickel plating containing one of the three additives is higher than that of the nickel plating containing phosphorus $(22,24$, and $25 \Omega$ when using 2-mercaptobenzimidazole, thioglycolic acid, and 2mercaptobenzothiazole, resp.); however, the best result for electrical resistivity is obtained in the case of the nickel plating containing all the three additives.

The change in the electrical properties of the substrate depends on the nickel-plating layer. Layers that have a high phosphorus content are less conductive than copper. The resistivity of a layer with low phosphorus was $20 \mu \cdot \mathrm{cm}$ [25]. For applications that require low electrical resistivity, thin plating layers are deposited. Heat treatment and chemical composition of the plating bath affect resistivity. Conductivity increased by two times because of precipitated phosphorus in the heat-treated nickel plating. Phosphorus affects the thermal expansion of the nickel layer [5]. From these results in Table 10, it is seen that the addition of 2-mercaptobenzimidazole, 2-mercaptobenzothiazole, and thioglycolic acid increases electrical resistivity.

Penetration of the nickel layer is perfect on several substrates [18]. Microscopic particles on the substrate were cleaned using a bath solution, creating a metallic bond between the nickel layer and the substrate surface. The initial reaction occurred on all catalytic materials but not on noncatalytic metals for which penetration decreased. The reaction was initiated by applying a very thin electroplated nickel layer. On aluminum, hydrogen in the nickel layer was released by a baking process at $130-200^{\circ} \mathrm{C}$ for $1-4 \mathrm{~h}$. Diffusion of the nickel layer into the substrate increases the bond strength. The adhesive strength between the nickel plating and steel was $30,000-60,000$ psi. Further, cracks, blisters, 
discoloration, or peeling of the plating was not observed after the tests [21].

Studies performed till date show that the adhesion capability of the nickel plating on to the metal surface is better than that of other nickel alloy platings. Charpy impact tests have shown that the addition of 2-mercaptobenzimidazole, thioglycolic acid, and 2-mercaptobenzothiazole results in increased adhesion capability. The most important feature of electroless nickel plating is its hardness. Microhardness of the plated nickel layer was $500-700 \mathrm{HV} 100$. This value is equal to approximately $45-58 \mathrm{HR}$ (Rockwell), which is the same as that for hardened alloy steel [21].

Because of the thermal properties of materials, such as brass, copper, and stainless steel, and the specific properties of the substrate, high temperature treatment could not be applied. In this case, if treatment was performed at a lower temperature for a long time, the required hardness could have been obtained.

A Rockwell hardness of 950-1000 was obtained after heat treatment at $340^{\circ} \mathrm{C}$ for $4-6 \mathrm{~h}$ or at $290^{\circ} \mathrm{C}$ for $10-12 \mathrm{~h}$, while lower hardness was obtained upon heat treatment at $260^{\circ} \mathrm{C}$. A small increase was obtained upon heat treatment at $230^{\circ} \mathrm{C}$ and lower temperatures. Hardening treatment is not preferred at lower temperatures. As such, heat treatment was performed for $2-4$ hat $180-200^{\circ} \mathrm{C}$ to increase the adhesive strength between the substrate and plating. It was also performed to decrease the tension by removing hydrogen from the plating layer.

Hardness is one of the most important parameters used in deciding the industrial value of plated materials. Therefore, the hardness obtained in the case of electroless nickel plating, $500-700 \mathrm{HV}$, is a major disadvantage. In the present study, this problem was solved by increasing the hardness to $785 \mathrm{HV}$.

The elongation changed with change in the nickel-plating composition, and the resistance to elongation was higher than several engineering materials such as zinc and copper. A thin electroless nickel plating is quite flexible and, unlike an electroplated layer, does not crack upon bending. However, with increased thickness of an electrolessly plated layer, brittleness increases. Therefore, electroless plating can be performed on all shapes. However, it cannot be applied on substrates that work by bending, because small deformations can cause corrosion and low abrasion resistance. Low phosphorus ratio or sulfur containing agents increase the resistance to rupture. An increase in the phosphor concentration of $1 \%$ in electroless nickel platings results in an elongation of $1.2 \%$ [5]. Tensile strength is another parameter that must be closely monitored for ensuring the suitability of using nickel platings in industrial applications. As compared to the nickel plating containing phosphorus $(3500 \mathrm{~N})$, the phosphorusfree plating obtained in this study had a higher tensile strength of $3800 \mathrm{~N}$. A phosphor concentration of $1 \%$ ensures a tensile strength of $100 \mathrm{~N}$.

The density of electroless nickel plating decreases as the phosphorus content increases; the density of electroless nickel with low phosphorus content was $8.5 \mathrm{~kg} \cdot \mathrm{cm}^{-3}$, whereas the density of electroless nickel with high phosphorous content was $7.75 \mathrm{~g} \cdot \mathrm{cm}^{-3}$ [5]. According to these results, an
TABLE 12: Falex testing results of electroless nickel bath solutions.

\begin{tabular}{lc}
\hline Plated material in each bath solution & Maximum load $(\mathrm{Nm})$ \\
\hline 1 & 338.9 \\
2 & 451.9 \\
3 & 338.9 \\
4 & 107.3 \\
5 & 158.1 \\
\hline
\end{tabular}

increase in the concentration of phosphor in the nickelplating bath of $1 \%$ increases the density by $0.75 \mathrm{~g} / \mathrm{cm}^{3}$. In this study, the density of the plated electroless nickel was found to be in the range of $7.28-7.32 \mathrm{~g} \cdot \mathrm{cm}^{-3}$.

The elongation in the case of electroless nickel plating changes with the composition of the plated layer. Nickel alloy shows better resistance to elongation than does zinc. While the elongation is $1.2 \%$ in other nickel-plating processes, the elongation of our nickel-plating ranges between $1.1 \%$ and $2.4 \%$.

Optical microscopic studies performed on five plated materials obtained using plating baths with different compositions show that the plating thicknesses in all the cases are almost the same. The bath compositions used are listed in Tables 3-7. It is seen that as the porosity increases, the plated layer is deformed. Effective precleaning of the porous metal surface results in a uniform plating that is well adhered to the substrate. The plating thicknesses of the samples with different pore shapes are almost the same, $10-12 \mu \mathrm{m}$. The optical microscope images showed differences depending on the bath composition and the layer topography. It is possible to adjust the bath solution to obtain both matte and bright finishes. A mirror-plating layer can be deposited on the polished surface to obtain a mirror finish. Such brightness cannot be achieved on sandblasted, polished or cast surfaces. If corrosion protection, perfect elongation, low stress, and thick plating are required, the plating should not be bright [26]. Abrasion implies the removal of material from the surface. Electroless nickel plating imparts perfect resistance to abrasion. Laboratory experiments show that resistance to abrasion of the heat-treated electroless plated nickel is the same as hard chromium plating. This shows the need for high alloy material or hard chromium plating for any surface.

The abrasion resistance of the samples in this study is confirmed to be excellent by the Falex method. Hence, no other protective layer such as chrome plating is necessary on the nickel plating. The Falex testing results for each sample are listed in Table 12 for the maximum load applied. The maximum load listed for examples 1-3 was without breaking, while the maximum load for examples $4-5$ was just prior to breaking.

As seen from the Falex results (Table 12), it is observed that if the amounts of organic additive increases, the plated layers have more strength during the Falex abrasion test for all five baths.

The most significant mechanical property in the case of electroless nickel plating is the friction characteristic. The friction coefficient in the case of traditional electroless 
nickel plating is 0.13 . The friction coefficient obtained for the nickel plating in this study is $0.13,0.12$, and 0.115 for the addition of 2-mercaptobenzimidazole, thioglycolic acid, and 2-mercaptobenzothiazole, respectively, and 0.11 when all the three additives are added to the plating bath.

The friction characteristics of the electroless nickel-plated layer were perfect. The friction coefficient of the lubricated layer was 0.13 , and it was 0.6 for the unlubricated layer. This prevents over heating during the working of the material and prevents negative effects like overexpansion and contraction created because of the heating and cooling by friction. The electroless nickel plated in this study could be soldered easily. In particular, in the electronics industry, nickel-plated metals such as aluminum are prepared using electroless nickel plating. Because the welding point of nickel alloy is lower than pure nickel and impurities such as phosphorus in the alloy diffuse into steel, the steel becomes brittle, making welding difficult. Increasing the phosphor concentration by $1 \%$ increases the melting point of nickel platings by $50^{\circ} \mathrm{C}$.

Using high purity stainless steel anodes, a different process has been reported in literature [21]. Electroless nickel-plated layers are easily soldered using an acidic flux, without which heat treatment can make soldering difficult. A solderability test was designed to evaluate the solderability and weldability of the soldering material to the electroless nickel plating. The test was performed by soldering the plated materials and evaluating the soldering points using a pull test for mechanical characterization of the soldering interface.

Solderability and weldability of the nickel plating play an important role for engineering applications. The nickel plating in our study shows superior soldering properties as compared to the traditional electroless nickel plating and hence can be used in electronic circuits, which in turn can be used to produce electronic cards. Because traditional nickel plating involves the use of phosphorus, the solderability is weak; the solderability, however, increases with a decrease in the phosphour concentration $(10 \%>P>1 \%)$ in the plating. The solderability and weldability of our nickel plating are superior to those in traditional electroless plating because (1) phosphorus is not used and (2) the combination of 2-mercaptobenzimidazole, 2-mercaptobenzothiazole, and thioglycolic acid increases the welding point of the nickel plating.

Electroless plating isolates the substrate from the ambient entirely. Electroless nickel plating imparts corrosion resistance to the material depending on the phosphorus ratio in the electroless nickel layer, plating thickness, surface pretreatment, final treatment after plating, and the substrate. It provides resistance because of its passiveness, which changes depending on the phosphorus ratio [21].

Because it provides perfect corrosion resistance, it can be used for designing a plating material. The plated material should not become harder after plating, because it lowers the corrosion resistance [21].

Electroless nickel plating results in a more amorphous structure than electroplating. Heat treatment affects the corrosion resistance provided by nickel plating because the phosphorus ratio decreases in heat-treated nickel layers, and the amorphous structures lose their properties. An investigation of the corrosion resistance to salt spray showed that a phosphor concentration of $1 \%$ increases the corrosion life by $5 \mathrm{~h}$ [5]. Active/passive small corrosion cell points occur in the nickel-plating layer and they diffuse into the entire layer. The amorphous structures convert into structures with microcracks because of physical changes. Corrosion resistance of the nickel layer decreases if its hardness increases because of heat treatment. Therefore, if corrosion resistance of the material has to be retained, heat treatment should not be performed [21].

Electroless nickel plating has been widely used in the metal industry because of advantages such as high hardness, excellent abrasion resistance, uniform plating thickness, and superior corrosion resistance. The high corrosion resistance required for nickel plating is generally realized by means of Ni- Alloy plating, but such alloys are not required to achieve high corrosion resistance in the present study. High corrosion resistance is obtained by using very small amounts of 2-mercaptobenzimidazole, 2-mercaptobenzothiazole, and thioglycolic acid. The corrosion resistance life in our nickel plating is twice that observed with conventional processes, as revealed by salt spray tests.

2-Mercaptobenzimidazole, 2-mercaptobenzothiazole, and thioglycolic acid were used in different concentrations in nickel-plating baths. It was found that, when used separately in high concentrations, they yielded good results.

When 2-mercaptobenzothiazole is used in concentrations higher than $5 \mathrm{~g} / \mathrm{mL}$, it results in bright nickel platings. 2Mercaptobenzothiazole can also reduce the brittleness of nickel platings when used in a concentration of approximately $4 \mathrm{~g} / \mathrm{mL}$. Further, these chemical additives are also suitable for reducing the waste water generated from nickelplating baths and for decreasing the amounts of chemicals used in the baths.

Thioglycolic acid is used for varying the $\mathrm{pH}$. It can also be used for decreasing the energy consumption rates corresponding to 2-mercaptobenzothiazole and 2-mercaptobenzimidazole. For instance, the use of thioglycolic acid changes the energy-consumption rate for 2-mercaptobenzothiazole to $1000 \mathrm{~A} \mathrm{~h}$ and that for 2-mercaptobenzimidazole to $1500 \mathrm{~A} \mathrm{~h}$.

\section{Conclusion}

The use of electroless nickel plating began in the last few years and its usage has increased rapidly. The uniform plating thickness realized, suitability of Ni plating on all materials, corrosion resistance, abrasion resistance, and high hardness make Ni plating applicable in many industries.

In this study, three different materials-2-mercaptobenzimidazole, 2-mercaptobenzothiazole, and thioglycolic acid-were used for improving the electroless nickel-plating technique. The effects of these components were investigated, and it was observed that 2-mercaptobenzimidazole improved performance by disrupting the crystal structure. Further, although the other components also affected brightness, the effect of 2-mercaptobenzothiazole was most significant. Thioglycolic acid helped in the formation of the crystal structure. As the plating process proceeded, crystal growth occurred, resulting in matte plating, and the plating speed reduced. The 
individual concentrations of the three chemical components in the electroless nickel-plating bath were not more than $5 \mathrm{~mL} / \mathrm{L}$; if this amount was increased, the plating speed decreased. Moreover, upon replenishing, if the amounts of these chemical compounds were more than $5 \%$ of the initial amounts, plating stopped. If each chemical compound was $2.5 \mathrm{~mL} / \mathrm{L}$ or less, the baths could work without additional chemicals for $2 \mathrm{~h}$. It is determined that the most appropriate amounts of organic chemicals are between 1.5 and $2.5 \mathrm{~mL} / \mathrm{L}$. Based on these results, the optimum amounts of chemical compounds in the electroless nickel-plating baths should be $3 \mathrm{~g} / \mathrm{L}$ of 2-mercaptobenzimidazole, $4 \mathrm{~g} / \mathrm{L}$ of thioglycolic acid, and $2 \mathrm{~g} / \mathrm{L}$ of 2 -mercaptobenzothiazole.

Thus, in this study, several properties of electroless nickel were improved by using cheaper and easily available organic chemicals. Further, lower deposition rates compared to traditional electroless nickel bath were achieved, welding characteristics were improved, analytical control of the bath chemicals was made easier, uniform coating thickness on complex objects was achieved, and the hardness of plated materials was increased to $480 \mathrm{HV}$, which is higher than that in the case of electrodeposited nickel $(200 \mathrm{HV})$. In addition, the plating hardness could be increased to $1050 \mathrm{HV}$ by heat treatment at $400^{\circ} \mathrm{C}$ for $1 \mathrm{~h}$. Other improvements include about $1-3 \%$ elongation and higher wear resistance, solderability, brazeability, and corrosion resistance than those in the case of traditional nickel and nickel alloy plating.

\section{Conflict of Interests}

The authors declare that there is no conflict of interests regarding the publication of this paper.

\section{References}

[1] P. K. Yee, W. T. Wai, and Y. F. Khong, "Palladium-copper inter-diffusion during copper activation for electroless Nickel plating process on Copper power metal," in Proceedings of the 21st International Symposium on the IEEE Physical and Failure Analysis of Integrated Circuits (IPFA '14), pp. 219-222, IEEE, Singapore, July 2014.

[2] Z. Shao, Z. Cai, R. Hu, and S. Wei, "The study of electroless nickel plating directly on magnesium alloy," Surface and Coatings Technology, vol. 249, pp. 42-47, 2014.

[3] P. Liu, C. Li, X. Liang et al., "Recovery of high purity ferric phosphate from a spent electroless nickel plating bath," Green Chemistry, vol. 16, no. 3, pp. 1217-1224, 2014.

[4] S. Fujii, H. Hamasaki, H. Takeoka, T. Tsuruoka, K. Akamatsu, and Y. Nakamura, "Electroless nickel plating on polymer particles," Journal of Colloid and Interface Science, vol. 430, pp. 47-55, 2014.

[5] J. Rajaguru, M. Duke, and C. Au, "Development of rapid tooling by rapid prototyping technology and electroless nickel plating for low-volume production of plastic parts," International Journal of Advanced Manufacturing Technology, vol. 78, no. 1-4, pp. 31-40, 2015.

[6] Y.-J. Yim, K. Y. Rhee, and S.-J. Park, "Influence of electroless nickel-plating on fracture toughness of pitch-based carbon fibre reinforced composites," Composites Part B: Engineering, vol. 76, pp. 286-291, 2015.
[7] G.-P. Jin, Y. Fu, X.-C. Bao, X.-S. Feng, Y. Wang, and W.-H. Liu, "Electrochemically mediated atom transfer radical polymerization of iminodiacetic acid-functionalized poly(glycidyl methacrylate)grafted at carbon fibers for nano-nickel recovery from spent electroless nickel plating baths," Journal of Applied Electrochemistry, vol. 44, no. 5, pp. 621-629, 2014.

[8] L. Li, N. Takahashi, K. Kaneko, T. Shimizu, and T. Takarada, "A novel method for nickel recovery and phosphorus removal from spent electroless nickel-plating solution," Separation and Purification Technology, vol. 147, pp. 237-244, 2015.

[9] X. Shu, Y. Wang, C. Liu, A. Aljaafari, and W. Gao, "Doublelayered $\mathrm{Ni}-\mathrm{P} / \mathrm{Ni}-\mathrm{P}-\mathrm{ZrO}_{2}$ electroless coatings on AZ31 magnesium alloy with improved corrosion resistance," Surface and Coatings Technology, vol. 261, pp. 161-166, 2015.

[10] W. Liu, Q. Huang, and G. Hu, "A novel preparation route for multi-doped $\mathrm{LiFePO}_{4} / \mathrm{C}$ from spent electroless nickel plating solution," Journal of Alloys and Compounds, vol. 632, pp. 185189, 2015.

[11] S. Tengsuwan and M. Ohshima, "Supercritical carbon dioxideassisted electroless nickel plating on polypropylene-the effect of copolymer blend morphology on metal-polymer adhesion," The Journal of Supercritical Fluids, vol. 85, pp. 123-134, 2014.

[12] K. Y. Lee, J. T. Huang, P. S. Chao, J. M. Lin, and H. J. Hsu, "An integrated electroless nickel plating process for fabrication of CMOS-MEMS probe chip," Microelectronic Engineering, vol. 113, pp. 147-151, 2014.

[13] P. Sittisart, M. M. Hyland, M. A. Hodgson, C. Nguyen, and A. Fernyhough, "Preparation and characterization of electroless nickel-coated cellulose fibres," Wood Science and Technology, vol. 48, no. 4, pp. 841-853, 2014.

[14] H. Y. Lee, B. W. Cho, and J. K. Lee, "U.S. Patent No. 8,801,916," US Patent and Trademark Office, Washington, DC, USA, 2014.

[15] O. O. Ajibola, D. T. Oloruntoba, and B. O. Adewuyi, "Effects of hard surface grinding and activation on electroless-nickel plating on cast aluminium alloy substrates," Journal of Coatings, vol. 2014, Article ID 841619, 10 pages, 2014.

[16] X.-H. Zhu, F. Xie, J. Li, and G.-P. Jin, "Simultaneously recover $\mathrm{Ni}, \mathrm{P}$ and $\mathrm{S}$ from spent electroless nickel plating bath through forming graphene/NiAl layered double-hydroxide composite," Journal of Environmental Chemical Engineering, vol. 3, no. 2, pp. 1055-1060, 2015.

[17] M. Jagannatham, S. Sankaran, and H. Prathap, "Electroless nickel plating of arc discharge synthesized carbon nanotubes for metal matrix composites," Applied Surface Science, vol. 324, pp. 475-481, 2015.

[18] T. Nagano, H. Mitamura, Y. Yamashita, N. Yanase, H. Suzuki, and H. Naganawa, "Continuous liquid-liquid extraction of nickel from simulated electroless nickel plating liquid wastes by using a counter current emulsion flow extractor," Solvent Extraction Research and Development, vol. 21, no. 1, pp. 111-117, 2014.

[19] K. Miyama, K. Yoshida, S. Saitou, and T. Takashima, "Effects of internal stress of electroless Ni plating on solder joining strength," in International Conference on Electronic Packaging and iMAPS All Asia Conference (ICEP-IACC '15), pp. 800-803, Kyoto, Japan, April 2015.

[20] W. Zhu, Y. C. Zhou, J. W. Guo, L. Yang, and C. Lu, "Quantitative characterization of the interfacial adhesion of Ni thin film on steel substrate: a compression-induced buckling delamination test," Journal of the Mechanics and Physics of Solids, vol. 74, pp. 19-37, 2015. 
[21] Y. Ren, G.-S. Zhou, D.-L. Chai, and X.-P. Qiao, "On the formation of the interlayer between Ni-P coating and AZ33 magnesium alloy substrate by means of in situ SEM observation," Chinese Chemical Letters, vol. 25, no. 6, pp. 947-952, 2014.

[22] V. G. Pol, M. M. Thackeray, K. Mistry, and A. Erdemir, “U.S. Patent No. 8,648,019," US Patent and Trademark Office, Washington, DC, USA, 2014.

[23] D.-W. Deng, C.-G. Wang, Q.-Q. Liu, and T.-T. Niu, "Effect of standard heat treatment on microstructure and properties of borided Inconel 718-TNMSC, The Chinese Journal of Nonferrous Metals, vol. 25, no. 2, 2015.

[24] Y. J. Ye, P. Y. Wang, Y. P. Li, and D. C. Yin, "HAp/Ti ${ }_{2} \mathrm{Ni}$ coatings of high bonding strength on Ti-6Al-4V prepared by the eutectic melting bonding method," Journal of Materials Science: Materials in Medicine, vol. 26, no. 2, article 81, 11 pages, 2015.

[25] C. K. Lee, C. S. Chang, A. H. Tan, C. Y. Yang, and S. L. Lee, "Preparation of electroless nickel-phosphorous- $\mathrm{TiO}_{2}$ composite coating for improvement of wear and stress corrosion cracking resistance of AA7075 in 3.5\% NaCl," Key Engineering Materials, vol. 656-657, pp. 74-79, 2015.

[26] J. Amer, "Influence of multiple electroless nickel coatings on beech wood: preparation and characterization," Composite Interfaces, vol. 21, no. 3, pp. 191-201, 2014. 

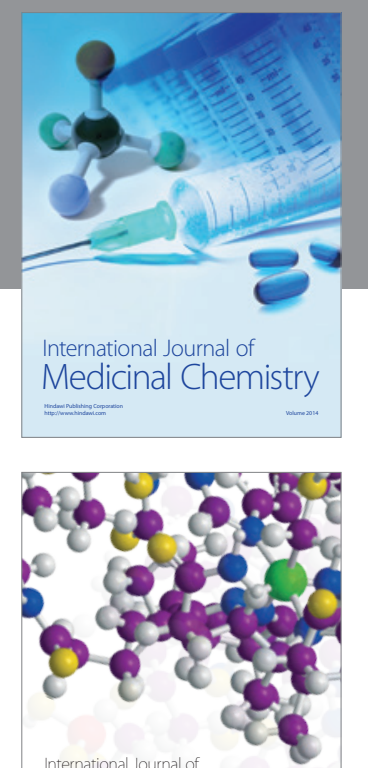

\section{Carbohydrate} Chemistry

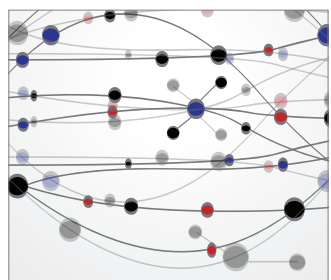

The Scientific World Journal
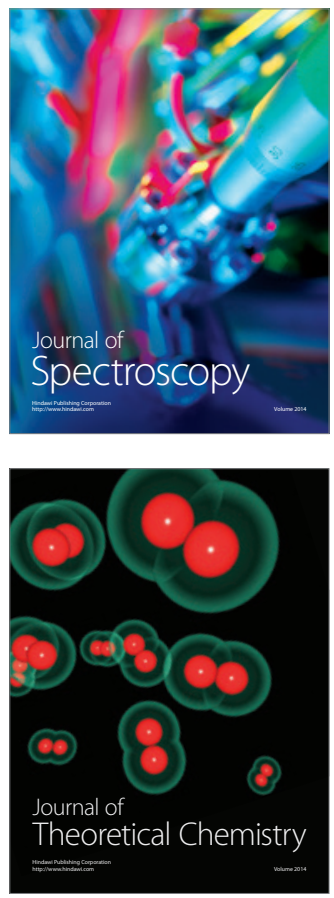
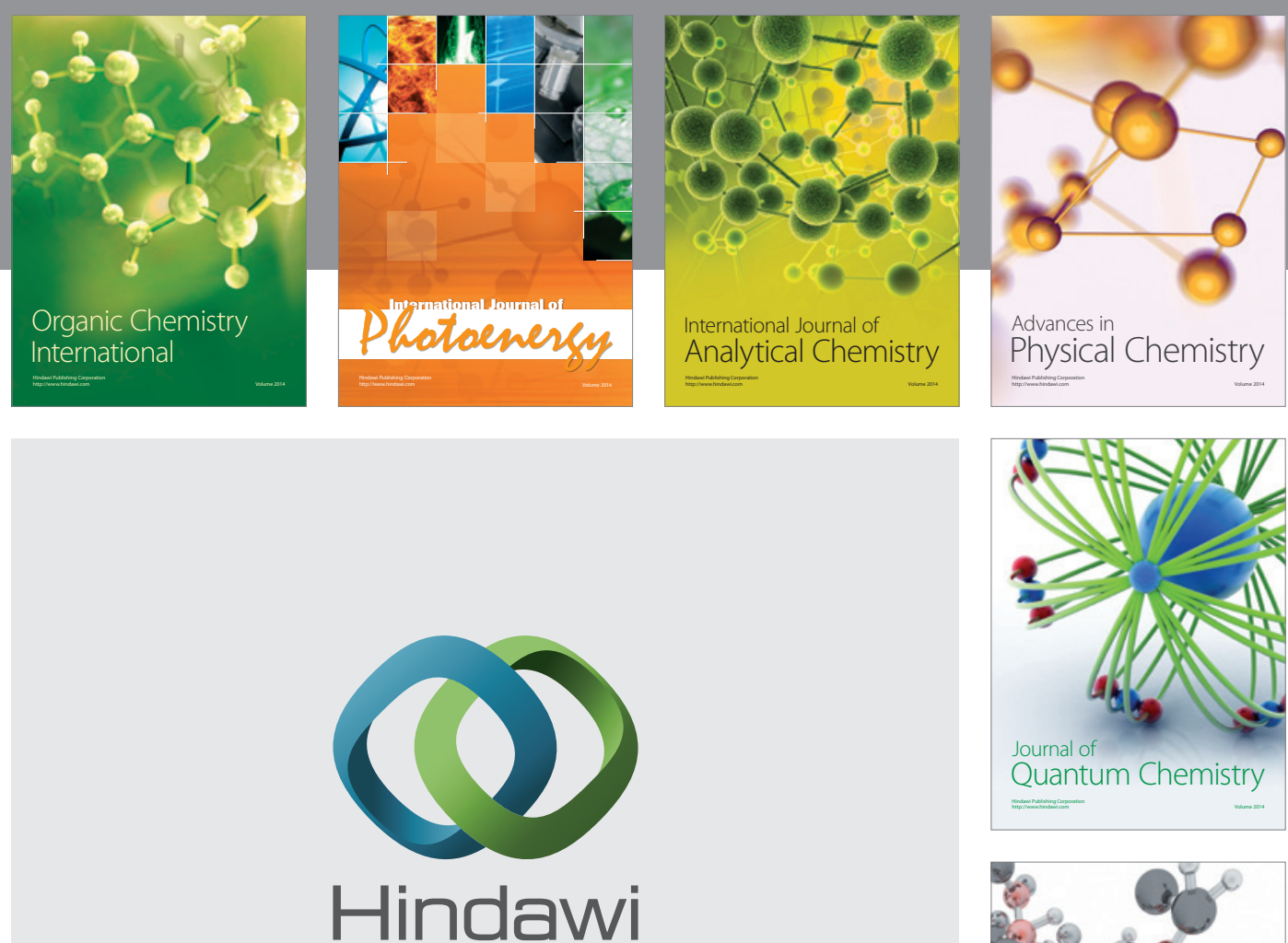

Submit your manuscripts at

http://www.hindawi.com

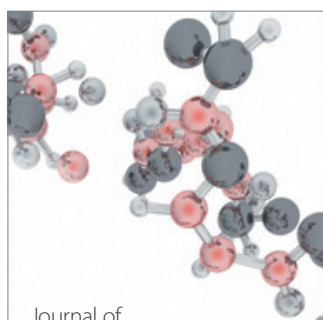

Analytical Methods

in Chemistry

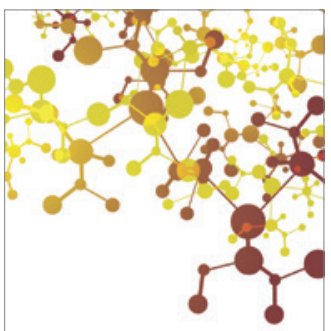

Journal of

Applied Chemistry

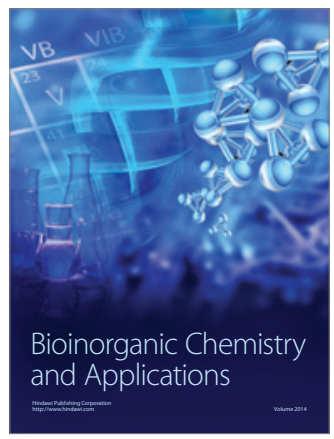

Inorganic Chemistry
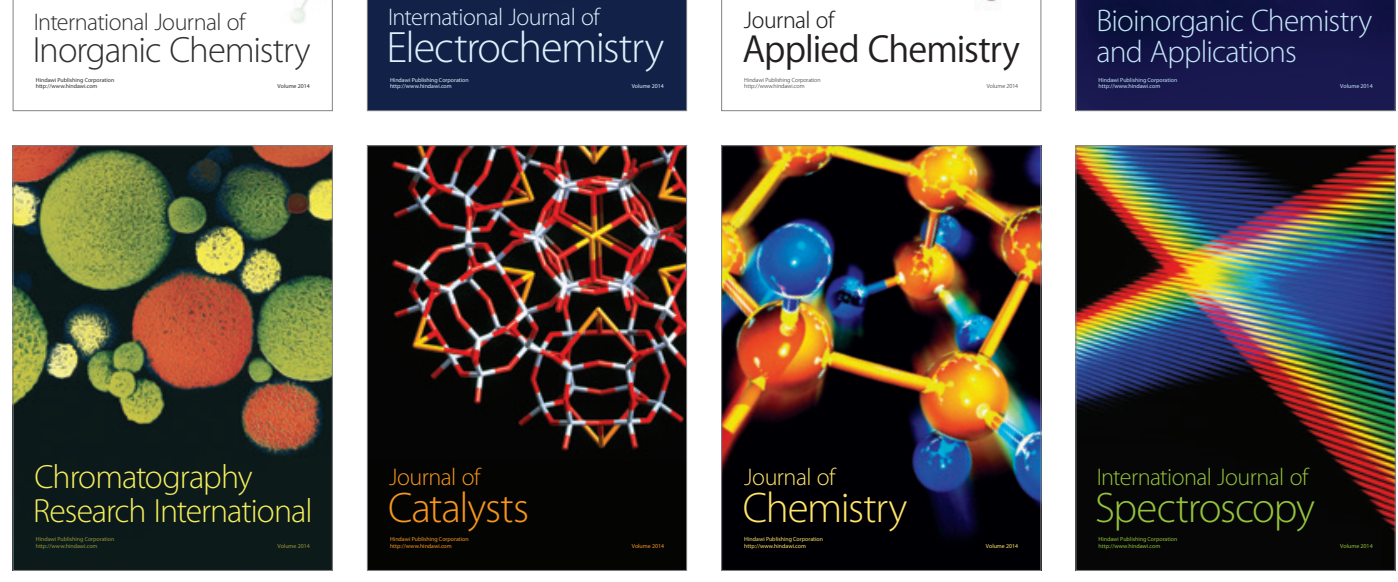